Para enlazar con este artículo / To link to this article:

http://dx.doi.org/10.14198/fem.2018.31.05

Para citar este artículo / To cite this article:

Martínez Fernández, Iván. «La implementación de la profilaxis preexposición en España sin las mujeres». En Feminismo/s, 31 (junio 2018): 107-125. Dosier monográfico: Sexo y bienestar. Mujeres y diversidad, coords. Carmen Mañas Viejo y Alicia Martínez Sanz, DOI: 10.14198/fem.2018.31.05

\title{
LA IMPLEMENTACIÓN DE LA PROFILAXIS PREEXPOSICIÓN EN ESPAÑA SIN LAS MUJERES
}

\section{THE IMPLEMENTATION OF PRE-EXPOSURE PROPHYLAXIS IN SPAIN WITHOUT WOMEN}

\author{
Iván MARTÍNEZ FERNÁNDEZ \\ Universidad de Valencia \\ orcid.org/0000-0002-5869-6114
}

\section{Resumen}

El objetivo del presente artículo es la exposición sucinta de la exclusión de las mujeres en la resolución del 27 de Julio de 2017 en el que se explicita el convenio de colaboración entre la Dirección General de Salud Pública, Calidad e Innovación y la empresa Gilead Servicios S.L.U. Este convenio es la formalización de la entrada e implementación de la profilaxis preexposición ante el VIH en el territorio nacional. La profilaxis preexposición ante el VIH es una novedosa intervención biomédica de carácter preventivo aplicada en personas que no viven con el VIH, que contiene como parte fundamental la ingesta diaria de un medicamento llamado Truvada, formado por dos componentes farmacológicos, emtricitabine y tenofovir, y capaz de inhibir la reproducción exponencial del virus en el caso de que se produzca la exposición de los tejidos del mismo al VIH sin variar de forma radical los hábitos sexuales.

Palabras clave: PreP, VIH, mujeres, prevención, exclusión.

\section{Abstract}

The objective of this article is the succinct exposition of the exclusion of women in the resolution of July 27, 2017 in which the collaboration agreement between the Public Health General Office, Quality and Innovation and the company Gilead 
Servicios S.L.U. This agreement is the formalization of the entry and implementation of pre-exposure prophylaxis against HIV in the national territory. Pre-exposure prophylaxis against HIV is a novel biomedical intervention of a preventive nature applied in people who do not live with HIV that contains as a fundamental part the daily intake of a drug called Truvada, composed of two pharmacological components, emtricitabine and tenofovir, which is able to inhibit the exponential reproduction of the virus in the event of the exposure of the tissues of the virus to HIV without radically changing sexual habits.

Keywords: PrEP, HIV, women, prevention, exclusion.

\section{INTRODUCCIÓN}

El ámbito de la prevención del Virus de Inmunodeficiencia Adquirida, en adelante VIH, para las mujeres está lleno de contradicciones. El rango que crea el mundo occidental de la prevención las relega a sujetos fuera de la emergencia que los HSH (hombres que mantienen relaciones sexuales con hombres) configuran. Las propias organizaciones sociales y gubernamentales las minusvaloran debido a que la interpretación de los datos epidemiológicos, fundamentalmente de la prevalencia y de la incidencia, las imagina como sujetos fuera de la emergencia epidemiológica.

El VIH tiene como forma principal de transmisión la sexual. La prevención de la transmisión sexual se convierte así en el elemento clave para controlarla.

Para una adecuada comprensión de los datos que aquí se van a exponer, conviene clarificar los siguientes conceptos medidores de la frecuencia de la enfermedad: incidencia y prevalencia. La prevalencia cuantifica la proporción de individuos de una población que padecen una enfermedad en un momento o periodo de tiempo determinado (Tapia Granados, Medidas de prevalencia y relación 105; Tapia Granados, Incidencia: concepto, terminología 216-218). Su cálculo se estima mediante la expresión:

$$
\mathrm{P}=\frac{\mathrm{N}^{\mathrm{o}} \text { de casos con la enfermedad en un momento dado }}{\text { Total de población en ese momento }}
$$

La incidencia se define como el número de casos nuevos de una enfermedad que se desarrollan en una población durante un período de tiempo 
determinado (Tapia Granados, Incidencia: concepto, terminología 103 y 140142). Hay dos tipos de medidas de incidencia: la incidencia acumulada y la tasa de incidencia, también denominada densidad de incidencia. La incidencia acumulada (IA) es la proporción de individuos sanos que desarrollan la enfermedad a lo largo de un período de tiempo concreto. La estimación más precisa es la que utiliza toda la información disponible y se denomina tasa de incidencia o densidad de incidencia (DI). Se calcula como el cociente entre el número de casos nuevos de una enfermedad ocurridos durante el periodo de seguimiento y la suma de todos los tiempos individuales de observación (Fernández, Pértegas y Valdés, Medidas de frecuencia de enfermedad).

Según los datos publicados por ONUSIDA en diciembre de 2017, entre 130.000 y 180.000 viven actualmente con VIH en España. De ellos, entre 44.000 y 65.000 serían mujeres. Menos de 500 serían mujeres adolescentes entre 10 y 19 años. Entre 1000 y 1500 tienen entre 15 y 24 años. Por último, las mujeres mayores de 50 años que viven en España con el virus del VIH son entre 12.000 y 17.000 .

La prevalencia entre mujeres de 15 a 49 años es de un 0,2\%. La de mujeres jóvenes entre 15 y 24 años representan menos de 0,1 . La prevalencia general para adultos en España es 0,4.

Actualmente tampoco existe ningún grupo que en España reivindique la prevención del VIH para mujeres o no con particular relevancia y notoriedad. Muchos discursos y relatos las conforman como sujetos continentes de una vulnerabilidad per se, homogénea, sin particularidades, plana.

\section{PREP Y LAS ORGANIZACIONES DE MUJERES DE LOS ESTADOS UNIDOS DE AMÉRICA (EUA)}

Aunque en el territorio español no suceda, existe una realidad más allá de los datos epidemiológicos patrios, pese a que los avances en la cura y la prevención del VIH han sido exponenciales: el obviar que, mundialmente, VIH, SIDA y mujer comparten escenarios cotidianos es temerario para conseguir que el cambio suceda y reducir el impacto de la epidemia. Las mujeres y, de manera concreta, las adolescentes y las mujeres más jóvenes, crean una profunda y ancha brecha de género que es obviada al interpretar los datos del territorio español. El "actúa local, piensa global" no es tomado en cuenta. 
Son multitud las asociaciones y entidades sin ánimo de lucro en el ámbito europeo y mundial que apoyan la profilaxis preexposición de una forma directa, determinada y sin complejos, mientras que España promociona, no desde las entidades de salud pública pero sí a través de entidades no gubernamentales como el BCN Checkpoint, este método de prevención para los hombres que mantienen relaciones sexuales con hombres, incluyendo a las mujeres transgénero o no. Las mujeres en España no son personas a las que, de momento, se haya dirigido una campaña específica para informarlas sobre esta forma de prevención. Tampoco ninguna entidad sin ánimo de lucro española ha promocionado la PrEP para ellas. Sin embargo, las organizaciones que a continuación se describen, provenientes del ámbito estadounidense, sí lo hacen. Cabe recordar que Estados Unidos es pionero en la promoción de PrEP para mujeres. A través de las siguientes descripciones se ampliará el conocimiento de las mismas.

HIVE es una de las organizaciones líderes en ofrecer información sobre salud reproductiva y está a la vanguardia en información sobre el VIH, al tratarla y ofrecerla de una manera innovadora, exhaustiva, amplia e integral desde finales de los años 90 del siglo pasado. Con un equipo de apasionados expertos, HIVE proporciona asistencia clínica, formación, capacitación, apoyo y una plataforma virtual para compartir las buenas prácticas. Su nombre se compone del nombre del virus en inglés al que se le ha añadido una "E" de empowerment (empoderamiento). Cuenta con el apoyo de la universidad de California, San Francisco (UCSF).

La misión de HIVE consiste en proporcionar bienestar sexual y reproductivo para individuos, familias y comunidades afectadas por el VIH en San Francisco y alrededores. La visión de HIVE se construye a través de una cosmovisión en la cual las personas afectadas por VIH tengan embarazos seguros, autonomía reproductiva, acceso a lo último en cuidado médico y gocen de una saludable vida sexual.

La práctica clínica en HIVE tiene como base el Hospital General Zuckerberg San Francisco. Allí se proporciona preconcepción de forma multidisciplinar, consulta médica para mujeres embarazadas, atención ginecológica y atención sanitaria referente a la salud sexual para mujeres viviendo con VIH, así como a sus parejas. La atención clínica incluye atención obstétrica para pacientes ambulatorios e internos de alto riesgo, atención obstétrica especializada en

Feminismo/s 31, junio 2018, pp. 107-125 
cuidado psiquiátrico, nutrición en la etapa prenatal y educación para la salud, servicio de guardería para los pacientes internos, servicios sociales integrales y servicio de realización de prueba de VIH y su derivación al departamento correspondiente.

En relación a la formación, HIVE ofrece y participa en acciones formativas sin restricciones fronterizas. Han conseguido posiciones de liderazgo en numerosos grupos de trabajo, incluido la "National Perinatal HIV Hotline", "Elimination of Mother-to-Child HIV Transmission Stakeholders Group", "Expert Panel on Reproductive Health for Women" and "Men living with HIV, and US Women" and "PrEP Working Group". También trabajan conjuntamente en la creación de guías de referencia y documentos normativos creados por la "DHHS Adult Antiretroviral Guidelines", "DHHS Perinatal Antiretroviral Guidelines", "Centers for Disease Control and Prevention (CDC)" y la organización mundial de la salud (OMS).

En su labor de consejero, HIVE tiene un fuerte compromiso para acabar con la transmisión del VIH. Aconsejan para eliminar la transmisión vertical, la que se produce de madre a neonato, facilitan y aumentan las posibilidades de acceso para mujeres transexuales y para las que no lo son. Cuentan con un completo e integral programa preventivo frente al VIH que incluye planificación familiar y una sexualidad empoderada. También se halla la inclusión de la salud sexual y reproductiva en la atención primaria, opciones de concepción segura para parejas afectadas por el VIH, así como salud reproductiva masculina.

Algunos de los donantes de HIV son: "Macy's, Mimi \& Peter Haas Foundation", "San Francisco Department of Public Health", "National Institutes of Health", "Elizabeth Taylor AIDS Foundation", "Gilead Sciences", "Project Inform", "Nike", "AIDSVu", etc.

Una parte fundamental de la estrategia de esta organización a favor del uso de la profilaxis preexposición por parte de mujeres son los hangouts que periódicamente organiza. Un hangout es una herramienta que ofrece la compañía de telecomunicaciones Google para la realización de videoconferencias, en este caso webminars, que no son más que seminarios que utilizan la red internet para su transmisión. También existen folletos informativos sobre la PrEP en inglés y en español. 
Una iniciativa proveniente de HIVE para el estado estadounidense de California es la denominada: "please, PrEP me". Consiste en un directorio de ubicación sensible y con capacidad de búsqueda de proveedores de la profilaxis en este estado. En su dirección web: http://www.pleaseprepme.org/es/, a la pregunta "¿por qué Please PrEP?" se responde de la siguiente manera: "Queremos facilitarle a la gente interesada en tomar la PPrE que encuentre un proveedor de PPrE que esté dispuesto a prescribírsela, iporque pensamos en un USTED empoderado!". Se ha de observar cómo la abreviatura cambia en este texto, procedente del entorno hispano estadounidense, y la asociación entre la profilaxis y el empoderamiento se realiza a través del uso del adjetivo "empoderado". Otro de los medios que usa HIVE para promocionar y dar soporte a esta forma de prevención es su blog, donde mujeres anónimas cuentan sus experiencias con la PrEP. Aunque la manera de animar a postear se mediatice a través de la entrega de 50 dólares como estipendio por cada entrada de blog publicada: "[...] We can work with you if you prefer to be anonymous. No professional writing skills necessary. We offer a $\$ 50$ stipend for each blog that we publish. [...]".

SísterLove, Inc. es una organización cuyo lema es el siguiente: "A women's AIDS and reproductive justice non profit focusing on women, particularly women of African descent". Aquí aparece uno de los grupos poblaciones clave que es objeto de campañas formativas y educacionales sobre la profilaxis antes de la exposición.

La misión de SísterLove es la de erradicar el impacto del VIH y de las opresiones de tipo sexual y reproductivo en la vida de las mujeres y sus comunidades en los EE.UU y el resto del mundo. Su cosmovisión trata de construir un mundo en el que todos y todas podamos vivir con dignidad y con semejantes condiciones protectoras sin importar la enfermedad, la discapacidad, la raza, el sexo, la clase, la identidad sexual, la identidad de género u otras distinciones de tipo político, económico, cultural, social o geográfico. Su valor fundamental se expone en la siguiente frase: "Healthy Loving is Healthy Living!" (Amar de forma saludable es vivir saludablemente).

En esta organización se encuentra una lideresa como fundadora, característica que la diferencia de las otras organizaciones. Su nombre es Dázon Dixon Diallo. Es una pionera en lo que se refiere a mujeres y VIH, así como en la defensa de los derechos sexuales y reproductivos de las mujeres. Uno

Feminismo/s 31, junio 2018, pp. 107-125 
de sus hitos es el haber desarrollado una estrategia de prevención denominado "Healthy Love". Una estrategia de prevención que ha sido incluida en el catálogo "Effective Interventions", bajo la caracterización de "HIP" (High Impact Prevention), recursos de alto impacto para la prevención del VIH del CDC (Centers for Disease Control and Prevention). "Healthy Love" consiste en una sesión única, basada en la evidencia. Se trata de una intervención sobre sexo seguro para mujeres afroamericanas centrada en el modelo de creencias de salud (health belief model), modelo psicológico que trata de explicar y anticipar los comportamientos relacionados con la salud de las personas y la teoría psicológica social-cognitiva. Los objetivos de "Healthy Love" son reducir los encuentros de sexo desprotegido con hombres y el número de parejas sexuales, así como incrementar la abstinencia sexual y el uso consistente de preservativos y otras barreras protectoras. Entre sus objetivos destaca, conseguir aumentar el número de mujeres que se realizan la prueban del VIH y que sean conocedoras del resultado de las mismas. La estrategia consigue estos objetivos a través del conocimiento de todo lo relacionado con el VIH/ SIDA, así como fomentando y ejercitando actitudes positivas respecto al sexo, a la sexualidad, a la autoeficacia y hacia el uso del condón. Esta organización destaca por haber establecido el primer programa de alojamiento para mujeres con VIH y sus hijos, haber adoptado la perspectiva de mujeres con VIH como lideresas en su lucha contra el VIH así como en la promoción de los derechos humanos de las mujeres. Dázon Dixon Diallo es la convocante de la única coalición nacional de mujeres centrada en el VIH y su prevención biomédica, "US Women \& PrEP Working Group".

\section{3. ¿QUÉ ES LA PROFILAXIS PREEXPOSICIÓN (PREP)?}

Jean-Michel Molina, profesor de enfermedades infecciosas en la Universidad de Paris Diderot, en el curso: HIV: Pre-exposure Prophylaxis - PrEP (2017), ofrecido por la EACS (European Aids Clinical Society) señaló que el principio básico de la estrategia de prevención llamada PrEP es la administración, a los individuos seronegativos, de la cantidad suficiente y necesaria para que sus concentraciones en los tejidos de entrada de virus, mucosa vaginal, mucosa anal, pene, mucosa oral y torrente sanguíneo, que consiga provocar que sus células no se infecten y así lograr el bloqueo del virus. El propósito es la

Feminismo/s 31, junio 2018, pp. 107-125 
protección de las personas VIH negativas contra la infección por VIH. Sin embargo, las personas usuarias deberían ser conscientes de que no impide la infección por otros agentes que generan otras infecciones de transmisión sexual.

Los fármacos antirretrovirales usados en la prevención del VIH denominada PrEP son, actualmente, una combinación de tenofovir disoproxil fumarate (TDF) y emtricitabine (FTC). Ambos son inhibidores de la transcriptasa inversa, análogos de los nucleósidos (NRTIs). Para conseguir la prevención de la infección por VIH de las células objetivo, que son las CD4 y las macrófagas, en los tejidos antes mencionados, han de actuar ambos fármacos antirretrovirales de forma sinérgica, estando presentes en las células objetivo en su expresión activa, es decir, como tenofovir diphosphate y emtricitabine triphosphate para conseguir bloquear los primeros pasos del ciclo vital del VIH antes de la integración viral en el genoma del huésped. Tenofovir diphosphate y emtricitabine triphosphate bloquean la actividad de la enzima denominada transcriptasa inversa en concurrencia con los nucleótidos endógenos y previenen la transformación del ARN viral que ha sido liberado en ADN. Entonces este ARN viral es degradado y desechado por la célula con la consiguiente detención de la posible infección por VIH. Hoy por hoy, TDF y FTC son administrados oralmente para la PrEP, pero otras formas de administración, por otras vías, están siendo investigadas.

Las razones de por qué el combinado de tenofovir/emtricitabine ha sido elegido como primer medicamento para la PrEP de primera generación, se basan en su potencia de actuación general sobre todos los subtipos de VIH y en su capacidad de tornarse rápidamente activo. También su perfil de seguridad y su tolerabilidad forman parte de las razones para promoverlo, así como la experiencia lograda como tratamiento de larga duración. Por último, su administración combinada en una única píldora, sin restricciones en relación a la comida, sus interacciones con un número reducido de fármacos, así como los ensayos clínicos con animales que indican un nivel de protección alta frente al SIV y el SHIV por medio del tenofovir administrado como PrEP, avalan su elección.

Underhill et al., Packaging PrEP to prevent HIV en 2010 plantean que el uso de PrEP ha de constar de cuatro componentes: el suministro de antirretrovirales por la propia persona, controles de seguridad (test de VIH cada tres

Feminismo/s 31, junio 2018, pp. 107-125 
meses, test de ITS], intervenciones conductuales (sexo seguro) e integración de PrEP dentro de un programa comprensivo de atención integral, así como test trimestrales de embarazo y revisiones ginecológicas en el caso de las personas con un tracto genital que esté compuesto principalmente de una vagina.

\section{LA EFICACIA DE PREP EN LOS ENSAYOS CLÍNICOS}

En cuanto a la eficacia de esta forma de prevención en las mujeres como key population se ha de mostrar la reducción del riesgo de adquisición del VIH de los ensayos clínicos en los que, exclusivamente, han participado mujeres. A los mencionados anteriormente, FEM-PrEP (6\%) y VOICE (-49\%), se han de añadir los que usaron como principio tenofovir en gel para su aplicación tópica. Estos son CAPRISA 004 con una eficacia del 39\% en régimen "bajo demanda", FACTS con un 0\% también "bajo demanda" y VOICE, de aplicación diaria, con un $-15 \%$. Dentro de la PrEP y su uso por parte de las mujeres, tiene una particular importancia la microbiota vaginal. En la conferencia sobre retrovirus e infecciones oportunistas (CROI 2017) fue expuesta la disonancia en la eficacia del gel usado como PrEP según hubiera o no hubiera determinadas bacterias en la vagina. Las participantes en cuya microbiota había un alto porcentaje de la bacteria denominada "Lactobacillus" se incrementó la eficacia de protección frente al VIH hasta un 61\%. Sin embargo, la eficacia se redujo hasta niveles cercanos al $18 \%$ en aquellas participantes en las que esta bacteria no era la predominante en su microbiota vaginal. Una de las conclusiones fue que la Gandnerella vaginales destruye tenofovir aplicado vía tópica (Burgener et al., Vaginal bacteria modify HIV).

Partners PrEP basado en tenofovir de forma oral y de administración diaria registró un $71 \%$ de eficacia para proteger del VIH y un 66\% cuando los fármacos fueron TDF/FTC. La alteración de la flora vaginal con valores bajos para la bacteria "lactobacillus" marcó un 77\% de eficacia para proteger frente al VIH. Independientemente, como sucedió en el estudio Partners PreP, se use una PreP oral con tenofovir o con tenofovir y emtricitabine, el proceso sistemático de metabolización de estos fármacos cuando son administrados de forma oral no puede ser modificado por la microbiota vaginal, es decir, este agente local no tiene capacidad de modificar su eficacia. El fomento y la promoción de la adecuada adherencia, así como el consuelling en PrEP son 
los puntos donde se ha de realizar el mayor esfuerzo, teniendo en cuenta también los determinantes biológicos.

Singular es el hecho de que ensayos clínicos que se efectuaron con el mismo tipo de antirretrovirales fracasaron en estudios clínicos que tenían como objeto de estudio su efectividad en mujeres. En abril del año 2011, el ensayo clínico denominado FEM-PrEP fue cancelado porque el análisis de los datos obtenidos, hasta entonces, indicaba la no efectividad de la reducción en el riesgo de adquisición del VIH entre mujeres heterosexuales. Del mismo modo, el estudio denominado VOICE (Vaginal and Oral Interventions to Control the Epidemic) no fue capaz de prevenir con valores significativos la infección por VIH. El editorial de Michael S. Saag, director de "AIDS Research Center" de la Universidad de Alabama en Birminghan, ayuda a comprender lo que supuso que no se demostrara que PrEP en su administración oral fuera eficaz en mujeres, y ayuda a comprender las investigaciones actuales en relación a los métodos de prevención del VIH para mujeres:

At first glance, the VOICE study appears to indicate that pre-exposure prophylaxis doesn't work in women in Africa and that we should move on to explore other approaches to the prevention of HIV transmission in highrisk settings [...] On further review, the study indicates that much more work is needed, not so much in the realm of understanding the biologic basis of pre-exposure prophylaxis as a preventive treatment, but rather in the realm of understanding behavioral barriers in the setting of strong social stigma (Saag 565).

Aunque muchas son las hipótesis, como por ejemplo las interacciones entre PreP en su forma oral y los anticonceptivos, la falta de éxito de estos ensayos clínicos y sus contradictorios resultados en relación a TDF-2 y Partners PrEP; consultado por correo electrónico, Laurent Cotte, especialista en VIH y hepatitis del hospital universitario de Lyon en Francia aportó la siguiente clarificadora respuesta: "the results for PrEP failure in FemPREP study (as in the Voice study) were clearly related to a low perceived risk for HIV in participants, resulting in a very low adherence to treatment. The mentionned hypothesis is non longer retained". 


\section{14 DE AGOSTO DE 2017, LA ENTRADA FORMAL DE LA PROFILAXIS PREEXOSICIÓN EN ESPAÑA}

El ministerio de Sanidad, Servicios Sociales e Igualdad a través de la resolución del 27 de Julio de 2017 detalla el convenio de colaboración entre la dirección general de salud pública, calidad e innovación y la empresa Gilead Servicios S.L.U. La publicación en el B.O.E. (Boletín Oficial del Estado) del 14 de agosto de 2017 es la entrada formal de la profilaxis preexposición en España. Pero es tan solo el umbral, ya que lo hace a través de "un estudio para valorar la factibilidad de la implementación de la PrEP como estrategia de prevención de la infección por el VIH en población de alto riesgo en el Sistema Nacional de Salud".

Las palabras claves de este camino elegido para iniciar la PrEP en España son "factibilidad de la implementación", es decir, si se puede hacer o no se puede hacer. Lo que denomina el ministerio como población de alto riesgo se resuelve en el epígrafe "participantes", que específica que "se incluirán un máximo de 400 hombres que tienen sexo con hombres (HSH) y personas transexuales". Estas últimas, sin diferenciar su aparato reproductor. Hecho este de relevancia, pues que sea uno u otro conllevaría revisiones ginecológicas y otro tipo de análisis que influirían en la factibilidad de la implementación de PrEP en el sistema nacional de salud (SNS). Si este convenio contemplara verdaderamente a las mujeres como sujeto de prevención ante el VIH y más concretamente, como destinatarias y probables usuarias de la profilaxis preexposición, incluiría entre sus variables los gastos que conllevarían las revisiones ginecológicas de las mujeres que participaran, la frecuencia de esas revisiones o la interconexión de la preconcepción y PrEP. La inclusión de las mujeres haría necesario incluir en el análisis de la factibilidad la realización cada 3 meses de un test de embarazo, ya que el hecho de estar embarazada significaría la paralización de la toma del fármaco que incluye la profilaxis preexposición. No contempla tampoco la participación hombres transgénero cuyos órganos genitales sean femeninos y que requieran de la supervisión ginecológica. Es, netamente, un estudio dirigido a hombres que mantienen relaciones sexuales con hombres. 


\subsection{El fármaco que contiene PrEP, un medicamento esencial para la OMS}

La reunión del $21 .^{\circ}$ comité de expertos que se celebró del 27 al 31 de marzo de 2017 en la sede la OMS en Ginebra (Suiza) decidió añadir la profilaxis previa a la exposición con tenofovir solo o en combinación con emtricitabina o lamivudina para prevenir la infección por VIH. La lista modelo OMS de medicamentos fue publicada en 1977 coincidiendo con la ratificación por parte de los gobiernos en la Asamblea Mundial de la Salud, órgano decisorio supremo de la OMS que se reúne en Ginebra en mayo de cada año, del enfoque "salud para todos" como principio vertebrador de las políticas sanitarias de la OMS y de los países.

Un medicamento esencial es un fármaco o una combinación de ellos que cubre las necesidades de atención de salud prioritarias de la población. Son elegidos en relación a la prevalencia de las enfermedades y a su seguridad, eficacia y costo-eficacia comparativa. Con ello se pretende que, en el marco de los sistemas de salud existentes, los medicamentos esenciales estén disponibles en todo momento, en cantidades suficientes, en las formulaciones farmacéuticas apropiadas, con una calidad garantizada y con un precio asequible para las personas y para la comunidad.

\section{EL CONCEPTO DE KEY POPULATION Y LAS MUJERES}

Este hecho, la consideración de esta forma de prevención como esencial por parte de la OMS, es fundamental para las key populations. Cuando ONUSIDA usa el término key population se refiere a los conjuntos poblaciones que con mayor probabilidad estén viviendo con el VIH, o aquellos que estén desproporcionadamente afectados por ello cuando se compara con la población en general, según los datos de que se disponga. Es importante tener en cuenta que los grupos poblaciones clave definidos por unos factores determinados concretos tienen una relación directa con la epidemia y con las relaciones sociales que se producen en ella. Si la reducción de las nuevas infecciones en un grupo poblacional determinado tuviera un impacto considerable en la trayectoria de la epidemia, en ese contexto determinado, entonces ese grupo poblacional podría ser considerado una key population. El involucramiento de los grupos poblaciones clave es fundamental para alcanzar una respuesta 
significativa y exitosa ante el VIH. Estos grupos son la clave en la epidemia y también son la clave en la respuesta para erradicarla.

Hombres homosexuales y otros hombres que tienen sexo con hombres, mujeres y hombres que son usuarios de drogas inyectables, trabajadores sexuales y personas transgénero son mayoritariamente marginados socialmente y el rostro de una innumerable trasgresión de los derechos humanos. Cada límite que se traspasa les hace más vulnerables ante el VIH. Los datos fiables y científicos recogidos en los diferentes países muestran como estos grupos poblacionales se encuentran en un alto riesgo de adquisición del VIH debido a la prevalencia informada. También la mortalidad y/o la tasa de incidencia son más altas cuando se comparan con la población general. Además, sus posibilidades de acceso a los servicios sociales y/o sanitarios son menores, en comparación con otros grupos poblaciones. Se hace necesario reconocer las necesidades de mujeres y niñas que trabajan en contextos de sexo comercial, usuarias de drogas y/o transgénero. En un importante número de contextos mujeres y niñas, así como adolescentes, sufren un gran impacto, desproporcionado en la mayoría de los casos, en relación a la epidemia de VIH y por ello deben ser consideradas como un grupo poblacional clave. También los contextos en los que las mujeres viven y las relaciones que se producen en esos contextos pueden crear vulnerabilidades añadidas.

Cuatro son los grupos poblaciones considerados como key population por ONUSIDA: trabajadores sexuales (hombres y mujeres), hombres que tienen sexo con hombres, usuarios de drogas inyectables (hombres y mujeres) y reclusos (hombres y mujeres). Como se puede observar las mujeres necesitan de un factor extra para ser consideradas como una población clave, a pesar de que haya mujeres que tienen relaciones sexuales con hombres que tienen relaciones sexuales con hombres. Obviar esa parte de la cadena es olvidar un punto en el continuum en la atención de la prevención del VIH. En muchos países, estos grupos poblaciones tienden a tener una mayor prevalencia de infección por VIH que la población en general, debido a los siguientes factores: participan en comportamientos que los colocan en alto riesgo de adquisición del VIH y se encuentran entre los más marginados y discriminados en relación a otros grupos sociales de la misma sociedad. Al mismo tiempo, los recursos destinados para la prevención y tratamiento del VIH para estos

Feminismo/s 31, junio 2018, pp. 107-125 
grupos poblaciones no tienen correlación con alta prevalencia de VIH que el análisis de los datos marca.

Dos son los conceptos fundamentales para comprender de una manera más adecuada el concepto de key population. Estos conceptos son: "riesgo de infección por VIH" y "vulnerabilidad ante el VIH".

El riesgo de infección por VIH puede ser definido como la probabilidad de que un individuo pueda llegar a ser infectado por VIH a través de sus propias acciones, a sabiendas o no, o a través de las acciones de otra(s) persona(s). Por ejemplo, una usuaria de drogas inyectables que utilice agujas contaminadas o teniendo sexo sin protección con múltiples parejas incrementa el riesgo de esa persona a la infección del VIH (ONUSIDA 23).

La vulnerabilidad ante el VIH refleja la incapacidad de un individuo o de un grupo poblacional para controlar su riesgo ante la infección por VIH. Pobreza, desigualdades de género y desplazamientos debido a conflictos o a desastres naturales son ejemplos de factores sociales y económicos que pueden intensificar la vulnerabilidad de la gente al VIH (ONUSIDA 35). Ambos, riesgo y vulnerabilidad, necesitan ser incluidos en las respuestas integrales a la epidemia.

Inserto en este discurso sobre los cuatro grupos poblaciones clave, ONUSIDA hace referencia a otro grupo que no es considerado como clave, pero que desde un punto de vista relacional es imprescindible para que la transmisión del virus continúe. Este grupo poblacional, satélite de los otro cuatro, sobre todo de las trabajadoras sexuales y de los hombres que tienen relaciones sexuales con hombres, es el varón heterosexual.

Se ha de clarificar la efectividad de esta forma de prevención en las mujeres en relación al tipo de exposición al virus. Al aplicar modelos predictivos se refleja que un $98 \%$ de la población femenina alcanzaría en la tercera dosis de TDF+FTC la protección deseada. El porcentaje de efectividad en una exposición ante el virus en un contacto sexual pene-vagina es de un 94\% (Donell et al. HIV Protective Efficcacy and) (Cotrell et al. A Translational Pharmacology appoach) con una toma cada 24 horas, aproximadamente, con un total de 6 o 7 por semana. Aunque el mínimo de adherencia requerida para proteger la mucosa vaginal ante el virus sería de un $85 \%$, es decir, 6 de las 7 dosis semanales. Mientras que con tan sólo 2 dosis de las siete requeridas se protegería la mucosa anal, es decir, tan sólo un 28\% de adherencia. Este modelo

Feminismo/s 31, junio 2018, pp. 107-125 
predictivo indica que entre dos y tres dosis por semana protegen a la mujer entre un $75 \%$ y un $90 \%$ en relaciones anales.

Se hace necesario exponer que los requerimientos de adherencia a la PrEP oral son diferentes entre hombres y mujeres. Si no se tiene esto en cuenta, la protección no tendría lugar, ya que Tenofovir (TFV) consigue una más rápida protección en la mucosa anal, mientras que Emtricitabine (FTC) lo haría con mayor rapidez en la mucosa vaginal.

Como ya se ha indicado key populations (poblaciones clave) son grupos, que, debido a sus específicos y particulares comportamientos de alto riesgo, incrementan su probabilidad de adquisición del VIH. Independientemente del tipo de epidemia o el contexto local, poblaciones vulnerables: grupos de personas que son de forma particular vulnerables a la adquisición del VIH en ciertas situaciones y/o contextos. Es responsabilidad de las autoridades de los diferentes países identificar estos grupos poblaciones adicionales con características específicas. La denominación usada por el ministerio: "grupos prioritarios que son más vulnerables" invisibiliza, de manera directa, a las mujeres que no entran dentro de las subcategorías de las key populations, que tampoco han sido incluidas en el estudio, y que solo conseguirían señalarse como sujeto de prevención a través de la definición de población vulnerable.

\section{UNA PERSPECTIVA MÁS COMPRENSIVA: CONTEXTOS DE VULNERABILIDAD}

Los entornos sociales, las mujeres que en ellos viven y el VIH configuran contextos cuya principal característica es la vulnerabilidad. El concepto de contexto de vulnerabilidad social permite superar el obstáculo que suponen, para ciertas entidades y grupos, los datos epidemiológicos que justifican la exclusión de las mujeres de las actividades de prevención del VIH. Las mujeres no necesitan vivir prácticas de riesgo, su vulnerabilidad social per se, por el hecho de que su género sea mujer, motiva y crea contextos donde esa vulnerabilidad articula situaciones en las que no es posible usar métodos de prevención que requieren la concomitancia del/de la compañero/a sexual.

Contexto es un espacio social definible y concreto, cruzado por los grandes ejes de la estructura social, como son el género o la clase, pero determinado también por otras circunstancias especiales: por ejemplo, por el hecho 
de pertenecer a una minoría étnica o a un grupo cultural no hegemónico; o por el hecho de encontrarse en las primeras etapas de la emigración. Esos espacios de condensación no son zonas sociales fijas e inmutables; son constructos analíticos, lugares donde se cruzan variables sociales y prácticas concretas que explican que la experiencia de unas personas o grupos sea diferente a la de otros. Son puntos de confluencia donde la violencia y el VIH cobran un sentido específico (Pernas 73). Por añadidura, el concepto de "contextos de vulnerabilidad" se refiere a lo que caracteriza estos espacios sociales: en ellos se producen desigualdades, que, al sumarse, hacen más probable la aparición de problemas de salud, económicos y sociales, y hacen más vulnerables a las personas que los padecen (Pernas 73).

Aunque la práctica sexual que conlleva más riesgo en la transmisión del VIH para la parte receptiva es la que consiste en la inserción del pene en el ano y puede producirse en ambos sexos y en todos los géneros, cobra una especial relevancia en la prevención para los hombres que mantienen relaciones sexuales con hombres debido a la prevalencia y a la incidencia. Con ello, a menudo se deja al resto de la población al margen de estas campañas de prevención, siendo algo residual lo dirigido de forma específica a las mujeres.

PreP no pretende reemplazar a otras estrategias de prevención del VIH porque no es $100 \%$ efectivo y mucho menos si se usa inconsistentemente o incorrectamente. Tampoco los planteamientos de uso se encuentran dirigidos hacia cualquiera.

La principal ventaja de PreP en su distribución oral es la de ser una forma de prevención ante el VIH altamente eficaz. Con ella, la lista de formas de prevención del VIH se amplía. Por ejemplo, PreP puede convertirse en un método de prevención para aquellas personas que no pueden negociar el uso del preservativo con su(s) pareja(s), personas en relaciones sero-discordantes (donde uno/a es seronegativo/a y el otro/a es seropositivo/a), personas que se inyectan drogas, pero no pueden conseguir nuevas agujas o no las reemplazan por la razón que sea; personas que no usan preservativos consistentemente... etc.

Otra ventaja de esta forma de prevención es que puede empezar a usarse en períodos de alto riesgo y cesar su uso en períodos de bajo riesgo de adquisición. 


\section{CONCLUSIÓN}

PreP es una intervención biomédica que no requiere de cambios inmediatos en las conductas sexuales para ser efectiva, aunque esta forma de prevención si incluye counsuelling destinado hacia esas conductas sexuales y hacia el estilo de vida. No se trata de convencer a las mujeres de este territorio de que viven en zonas de alta prevalencia, cuando no es así, o de que la incidencia del VIH en las mujeres que viven en España está aumentando, porque tampoco ésta es la realidad. Pero sí se trata de tomar conciencia de la exclusión de las mujeres de esta forma de prevención, que forma parte de la exclusión sistémica y larvada a ciertos servicios provenientes de las instituciones públicas y que se relacionan con la posición de la mujer en el mundo sustentadora de, entre otras lacras, la violencia hacia las mujeres. Y de como con cada nuevo encuentro sexual se configura una nueva prevalencia determinada por las personas que participan en él y un nuevo contexto en el que la mitigación de la variable "vulnerabilidad" ha de estar presente. No se trata de tantos por ciento, no se trata de números enteros, no se trata de números decimales, se trata de relaciones humanas y en ellas las mujeres están siempre presentes. Una de las claves para la cura de la infección del VIH es la de sacar al virus de los reservorios celulares en los que está escondido, la inclusión de las mujeres sin premisas epidemiológicas contribuiría a ello. La no inclusión de las mujeres en la entrada formal de PrEP en España es una muestra más de la exclusión de las mujeres de los ensayos clínicos, aunque, en este caso, con el matiz de "oportunidad pérdida" para reducir el impacto de la epidemia de VIH en territorio patrio. Una vez más, se torna necesario alejarse de la expresión relajada de los que nunca les ha sucedido nada.

\section{REFERENCIAS BIBLIOGRÁFICAS}

B.O.E. (Resolución de 27 de julio de 2017, de la Secretaría General de Sanidad y Consumo, por la que se publica el Convenio de colaboración entre la Dirección General de Salud Pública, Calidad e Innovación y Gilead Sciences, SLU., en el contexto del estudio sobre evaluación de la factibilidad de la implementación de la profilaxis preexposición (PrEP), como estrategia de prevención de la infección por el VIH en población de alto riesgo en el Sistema 
Nacional de Salud, BOE» núm. 193, de 14 de agosto de 2017, páginas 82288 a 82309).

Burgener, Adam, Nichole R. Klatt, Ryan Cheu, Kenzie Birse, Alexander S. Zevin, Michelle Perner, Laura Noël-Romas, Anneke Grobler, Garrett Westmacott, Irene Y. Xie, Jennifer Butler, Leila Mansoor, Lyle R. McKinnon, Jo-Ann S. Passmore, Quarraisha Abdool Karim y Salim S. Abdool Karim. "Vaginal bacteria modify HIV tenofovir microbicide efficacy in African women". Science 356.6341 (2017): 938-945.

Cottrell, Mackenzie, Kuo H. Yang, Heather M. A. Prince, Craig Sykes, Nicole White, Stephanie Malone, Evan S. Dellon, Ryan D. Madanick, Nicholas J. Shaheen, Michael G. Hudgens, Jacob Wulff, Kristine B. Patterson, Julie A. E. Nelson y Angela D. M. Kashuba. "A Translational Pharmacology Approach to Predicting Outcomes of Preexposure Prophylaxis Against HIV in Men and Women Using Tenofovir Disoproxil Fumarate With or Without Emtricitabine". The Journal of Infectious Diseases 214.1 (2016): 55-64.

Donnell, Deborah, Jared M. Baeten, Namandjé N. Bumpus, Justin Brantley, David R. Bangsberg, Jessica E. Haberer, Andrew Mujugira, Nelly Mugo, Patrick Ndase, Craig Hendrix y Connie Celum. "HIV Protective Efficacy and Correlates of Tenofovir Blood Concentrations in a Clinical Trial of PrEP for HIV Prevention". Journal of Acquired Immune Deficiency Syndromes 66.3 (2014): 340-348.

EACS (European Aids Clinical Society). Curso: HIV: Pre-exposure Prophylaxis PrEP by Iversity, 2017. 10 noviembre 2017. https://iversity.org/en/my/courses/ hiv-pre-exposure-prophylaxis-prep

Fernández, Salvador, Sonia Pértega-Díaz y Francisco Valdés Cañedo. "Medidas de frecuencia de enfermedad". Cuadernos de atención primaria 11.2 (2004): 101-105.

Pernas, Begoña, Marta Román y Elisa Arévalo. Estudio cualitativo: mujeres con VIH/ SIDA que están sometidas a violencia de género. Madrid: Dirección General de Atención Primaria, 2013.

Saag, Michael. "Preventing HIV in women - still trying to find their VOICE". The new england journal medicine 372.6 (2015): 564-566.

Tapia Granados, José A. Incidencia: concepto, terminología y análisis dimensional. Med Clin (Barc) 1994; 103: 140-142.

-. Medidas de prevalencia y relación incidencia-prevalencia. Med Clin (Barc) 1995; 105: 216-218.

Feminismo/s 31, junio 2018, pp. 107-125 
UNAIDS. Report on the global HIV/AIDS epidemic June 1998. 1998. 27 diciembre 2017 http://data.unaids.org/pub/report/1998/19981125_global_epidemic_ report_en.pdf

Underhill, Kristen, Don Operario, Margie Skeer y Matthew Mimiaga Ken Mayer. "Packaging PrEP to prevent HIV: An integrated framework to plan for pre-exposure prophylaxis implementation in clinical practice". JAIDS Journal of Acquired Immune Deficiency Syndromes 55 (2010): 8-13.

Feminismo/s 31, junio 2018, pp. 107-125 